\title{
El silencio del verbo según san Ireneo
}

\author{
Juan Carlos Alby \\ UNIVERSIDAD NACIONAL DEL LITORAL \\ UNIVERSIDAD CATÓLICA DE SANTA FE
}

En la vertiente asiática de la tradición Patrística, Justino inicia una reflexión que se proyectará sobre Ireneo y que tendrá, con diferencias de matices, su expresión correspondiente en los valentinianos. El tema se refiere a la supuesta ausencia del Logos durante la Pasión de Jesús, es decir, a la instancia en la cual el dinamismo divino se suspende en la cruz dejando al Jesús pasible a merced de la muerte.

El presente trabajo intenta destacar la manera en que Ireneo trata esta cuestión en el contexto de su polémica con los gnósticos, especialmente en aspectos decisivos de la cristología.

A partir de su recepción de las intuiciones de Justino, el obispo de Lyon desarrolla una argumentación antidocetista que, al mismo tiempo, afirma la naturaleza divina del Verbo sin menoscabo alguno y preanuncia las especulaciones más elaboradas que el curso posterior de la teología cristiana habría de sostener en torno al misterio del Logos.

\section{El ANTECEDENTE DE Justino}

Al comentar el episodio bíblico de Amalec relatado en Ex. 17, 8-15, Justino apela a la metáfora de la "mano oculta" de Dios y la traslada de la memorable escena del desierto al drama del Calvario:

«Y, en efecto, con mano oculta dícese que hacía el Señor la guerra a Amalec; y, sin embargo, no vais a negar que cayó Amalec. Y si solo con la venida gloriosa de Cristo dijeran ha de ser combatido Amalec, ¿qué significado tendría la Escritura que dice: "Con oculta

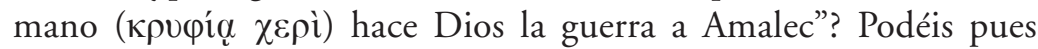
comprender que alguna oculta fuerza de Dios tuvo el Cristo cruci- 
ficado, cuando ante Él se estremecen los demonios y absolutamente todos los principados y potestades de la tierra» ${ }^{1}$.

Los momentos en que Amalec prevalecía en la batalla, encierran para el Santo una suspensión de la actividad divina que, más adelante en el mismo libro, la entiende a la manera de un silencio del Logos. Así, en el comentario al Sal. 21, 16:

«Profecía también de lo que, por voluntad del Padre, había de suceder a Cristo son las palabras: "Se secó como una teja mi fuerza, y mi lengua quedó pegada a mi paladar”. Porque la fuerza de su poderoso Verbo, con que confundía siempre a los fariseos y escribas que discutían con Él, y, en general, a los maestros de vuestro pueblo, quedó

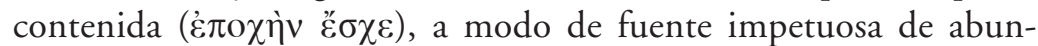
dante agua, cuya corriente fuera desviada, pues Él calló ( $\sigma \iota \gamma \eta ́ \sigma \alpha v \tau o \varsigma$ $\alpha \hat{v} \tau o \tilde{v})$ y ya ante Pilatos no quiso responder a nadie una palabra, como se cuenta en los Recuerdos de los Apóstoles» ${ }^{2}$.

La significatividad del silencio ya había sido atestiguada antes de Justino por Ignacio de Antioquía, quien con el participio $\sigma \imath \gamma \tilde{\omega} v$ indica el estado del Logos anterior a su perfecta manifestación:

«Más vale callar y ser que no hablar y no ser. Bien está el enseñar, a condición de que, quien enseña, haga. Ahora bien, un Maestro hay que dijo y fue. Mas también lo que callando hizo son cosas de su Padre. El que de verdad posee la palabra de Jesús, puede también escuchar su silencio $(\sigma l \gamma \tilde{\omega} v)$, a fin de ser perfecto. De esta manera, según lo que habla, obra; y por lo que calla, es conocido» ${ }^{3}$.

En el mismo contexto de los Padres Apostólicos, el antiguo documento cristiano conocido como Carta a Diogneto hace referencia al secreto en que Dios mantuvo su consejo, hasta que fue comunicado a tiempo en el Hijo, aun cuando pareciera que tal silencio denunciara una indiferencia hacia los hombres:

"Ahora bien, en tanto mantenía en secreto y se guardaba su sano consejo, parecía que no se cuidaba y que nada le importaba de nosotros, mas cuando nos lo reveló por medio de su Hijo amado y nos

1 Justino, Diálogo con Trifón (en adelante: Diál.) 49, 8; en: D. Ruiz Bueno, Padres Apologetas griegos (s. II), edición bilingüe completa griego-español (BAC, Madrid $\left.{ }^{3} 1996\right), 385$.

2 Justino, Diál. 102, 5, 482.

3 Ignacio de Antioquía, Carta a los Efesios XV, 1, en D. Ruiz Bueno, Padres Apostólicos, edición bilingüe completa griego-español (BAC, Madrid $\left.{ }^{6} 1993\right), 436$. 
manifestó lo que tenía preparado desde el principio, todo nos lo dio conjuntamente...» ${ }^{4}$.

Justino, en cambio, centrándose más en la pasión, ratifica lo dicho anteriormente en su exégesis del salmo al que considera una profecía del silencio del Verbo:

«Lo de: "Se secó, como una teja, mi fuerza, y mi lengua quedó pegada al paladar", era, como antes dije, profecía de su silencio, pues Él, que había convencido de ignorantes a vuestros maestros, no respondió en su pasión una palabra a nadie» 5 .

Según el Mártir, esta actitud por parte de Jesús, aparentemente pasiva e ignorante de lo que le había de acontecer, no era sino un disimulo para provocar la confusión de sus enemigos, de la misma manera en que Dios con la suspensión intermitente de su poder en aquella batalla del desierto, suscitó la confusión en los amalecitas:

"Y para que nadie objetara: ¿Es que ignoraba que tenía que padecer?, se añade inmediatamente en el salmo: "Y es cosa que yo no ignoro" (Sal. 21, 3). A la manera en que tampoco Dios ignoraba nada al preguntarle a Adán dónde estaba y a Caín por el paradero de Abel, sino que quería argüir a cada uno de lo que era y que a nosotros llegara el conocimiento de todo, al quedar consignado por escrito; así Jesús dio a entender que no obraba por propia ignorancia, sino que delataba la de quienes creían que no era Él el Cristo, y se imaginaban que le iban a dar muerte y que, como un hombre cualquiera, permanecería para siempre en la región de los muertos $»^{6}$.

El camino a la cruz, necesario para redimir el hombre, exigía el triunfo de sus enemigos y, en orden a esto, el Logos guardó silencio e impostó una ignorancia que lo dejó a merced de los poderes adversos. Con esta reflexión, Justino prepara el camino para el análisis que del mismo tema hará Ireneo, pero con la novedad de proyectar retrospectivamente el silencio del momento de la Pasión a las tentaciones de Jesús en el desierto.

\section{IRENEO Y LOS VALENTINIANOS}

La posición de Ireneo resulta particularmente interesante no solo por incorporar el episodio de las tentaciones de Jesús en su consideración del

\footnotetext{
4 Carta a Diogneto VIII, 10-11, en: D. Ruiz Bueno, Padres Apostólicos, 854.

5 Justino, Diál. 103, 9, 485.

6 Justino, Diál. 99, 3, 477.
} 
silencio del Verbo, sino también por las paradojas y tensiones que presenta su argumentación y que se resuelven en una síntesis antidocetista.

Ireneo enfrenta a los valentinianos, quienes distinguían entre el Cristo superior o Salvador, invisible, incomprensible e impasible, que descendió de los seres invisibles e inenarrables y el Jesús visible y pasible de la economía. Para confutarlos, el lugdunense enfatiza la asunción de la humanidad por parte del Logos e introduce uno de los conceptos más originales de su teología, a saber, el de recapitulación ( $\dot{\alpha} v \alpha \kappa \varepsilon \varphi \alpha \lambda \alpha i ́ \omega \sigma ı \varsigma)$ :

«No ven que el mismo Verbo (Jn. 1, 1-3) Unigénito (Jn. 1, 18), que siempre está presente en la humanidad (Jn. 1, 10), uniéndose y mezclándose con su creatura según el beneplácito del Padre, y haciéndose carne (Jn. 1, 14), es el mismo Jesucristo nuestro Señor, que sufrió por nosotros y se despertó por nosotros, y de nuevo vendrá en la gloria del Padre para resucitar a toda carne y para manifestar la salvación y para extender la regla del justo juicio a todos los que han sido hechos por él. Así, pues, como hemos demostrado, hay un solo Dios Padre, y un solo Cristo Jesús nuestro Señor, el cual vino para la salvación universal recapitulando todo en sí (Ef. 1, 10)» .

No obstante, en un texto sorprendente del mismo libro III, Ireneo distingue entre las propiedades del Hijo de Dios por generación del Padre de las del Hijo del hombre por generación de María:

«En cuanto hombre, lo era para ser tentado; en cuanto Verbo, para

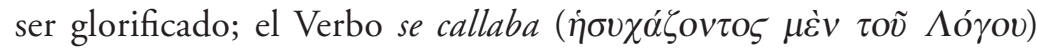
para que pudiera ser tentado, deshonrado, crucificado y muerto. $A b$ -

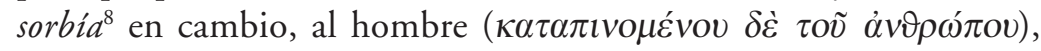

\footnotetext{
Ireneo, Adversus haereses (en adelante: Adv. haer.) III, 16, 6.
}

8 Seguimos aquí la traducción de Antonio Orbe en su Cristología gnóstica. Introducción a la soteriología de los siglos II y III, vol. II (BAC, Madrid 1976), 253. El mismo autor traduce en otro estudio por «devoraba»; cfr. A. OrBE, «El Espíritu en el bautismo de Jesús», en Gregorianum 76, 4(1995), 663-669 (aquí: 684). Este autor sigue la traducción francesa de F. SAGNARD, SC 211, 1952, 337: «était absorbé [dans le Verbe]... ». El verbo $\kappa \alpha \tau \alpha \pi i ́ v \omega$ significa, precisamente, «tragar», «engullir», "absorber», "consumir», "devorar»; cfr. F. I. ARzA, Diccionario griego-español (Sopena, Barcelona 1972), 738. Es el verbo que trae el texto griego de la edición crítica de A. Rousseau y L. Doutreleau, en: Irénée de Lyon. Contre les hérésies, Livre III, Tome II, SC 211 (Cerf, Paris 1979), 379. El mismo verbo aparece en 1 Co. 15, 53-54 y 2 Co. 5, 4, tal como lo señalan los mencionados autores en nota al pie de la citada página (ver nota a.). Por su parte, Carlos Ignacio González traduce

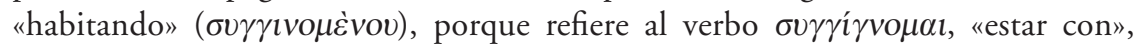
«habitar junto a», y justifica tal traducción diciendo que el texto latino "absorto 
que vence y soporta el sufrimiento y se comporta como hombre de bien, resucita y es asumido (al cielo)»?

El Verbo «se callaba», «suspendía su acción» ${ }^{10}$, pero esto de ninguna manera implica ausencia, tanto para eclesiásticos como para gnósticos. El carácter pasible de su naturaleza manifestado antes del bautismo y durante la Pasión, no negaba en absoluto la realidad del Verbo encarnado. Ireneo lo expresa más de una vez en su exégesis antiebionítica de Is. 7, 14, mientras que los valentinianos hablan de una sýstole o "contracción» del Espíritu antes que de una ausencia. Tal era la tesis de los valentinianos de Teódoto:

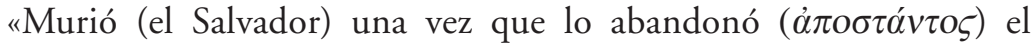
Espíritu que había descendido en él en el Jordán (Mt. 3, 16); no se trata de que este se haya transformado propiamente (oủ $i \delta i ́ \alpha$ $\gamma \varepsilon v o \mu \varepsilon ́ v o v)$, sino que se ha replegado ( $\sigma v \sigma \tau \alpha \lambda \varepsilon \dot{\varepsilon} v \sigma \varsigma)$, para que la muerte también actuase. Pues, ¿cómo habría muerto el cuerpo, estando presente en él la Vida? Porque de tal modo la muerte habría también dominado al Salvador, lo que es absurdo. La muerte, sin embargo, ha sido dominada con un engaño, ya que una vez muerto el cuerpo y dominado por la muerte, el Salvador, haciendo retroceder ( $\dot{\alpha} v \alpha \sigma \tau \tau \varepsilon i ́ \lambda o \varsigma)$ el rayo de la potencia que lo ha asaltado, ha destruido a la muerte y resucitado el cuerpo mortal, expulsadas las pasiones» ${ }^{11}$.

Las metáforas empleadas denotan la influencia de la teología solar sobre el pensamiento gnóstico, como puede apreciarse muy bien en los docetas de Hipólito:

«El mencionado Hijo Unigénito que procede de los eones superiores, al ver las formas venidas de lo alto transmutadas al introducirse en los cuerpos tenebrosos, quiso descender y rescatarlas. Supo, sin embargo, que ni siquiera los eones que forman parte de la multitud pueden soportar la visión del Pleroma de la totalidad de los eones,

autem homine in eo queod vincit et sustinet..." traduce erróneamente y desde una teología posterior que estaría imputando a Ireneo una fórmula monofisista. Cfr. C. I. GonzÁlez, Ireneo de Lión. Contra los herejes (Conferencia del Episcopado Mexicano, México 2000), Libro III, n. 269. Pero, como ya fue dicho, la última edición crítica trae el verbo $\kappa \alpha \tau \alpha \pi i ́ v \omega$ en vez de $\sigma v \gamma \gamma \dot{\gamma} \gamma v o \mu \alpha$.

9 Ireneo, Adv. haer. III, 19, 3.

10 A. Orbe, Cristología gnóstica II, p. 253, n. 157 y «El Espíritu...», 684 n. 47.

11 Clemente de Alejandría, Extractos de Teódoto (en adelante: ET) 61, 6-7, en: F. GARCía BAZÁn, La gnosis eterna. Antología de textos gnósticos griegos, latinos y coptos I (Trotta, Madrid 2003), 242. 
antes bien los corruptibles permanecen aterrorizados bajo la corrupción, ligados por la grandeza y la gloria de la potencia. Se contrajo ( $\sigma v \sigma \tau \varepsilon i ́ \lambda o \varsigma)$ entonces como un gran resplandor que se refleja en un cuerpo diminuto. O se podría comparar con más propiedad con la luz de la visión, encerrada bajo los párpados, que luego se remonta hacia el cielo y después de haber rozado los astros de aquel lugar se encierra de nuevo tras los párpados, tantas veces cuantas quiere» ${ }^{12}$.

Entre los epítetos del Verbo utilizados por los gnósticos, se destacan algunos de inspiración en la teología solar, tales como «Belleza perfec-

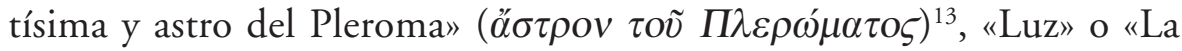
Luz» ( $\tau \dot{o} \varphi \tilde{\omega} \varsigma$ ), como lo denomina también Tolomeo, quien probablemente hace coincidir su origen con el fiat lux de Gén. 1, $3^{14}$. Los valentinianos aluden también a Jn. I, 5 y 9: «Él era la Luz verdadera....» ${ }^{15}$. Estos epítetos recogidos por Ireneo, ayudan a justificar la denominación de los ángeles del Logos como «satélites»:

"Junto con él fueron emitidos como satélites suyos, para honra de ellos (de los eones), ángeles de su mismo linaje» ${ }^{16}$.

El Unigénito se presenta fuera del Pleroma a la manera del sol vestido de rayos, proyectando al mundo sus perfecciones ${ }^{17}$. Los ángeles son al Cristo como los rayos al sol, efluvios vivientes que nacen de Él para acompañarlo siempre, así como las dýnameis acompañan a la sustancia. Tal relación se parece a la imagen presentada por Celso, de los funcionarios satélites que acompañan a los monarcas y emperadores:

«Consideremos ahora otro texto de Celso que dice así: "Un sátrapa, un gobernador, un general o un procurador del rey de los persas o del emperador romano, y hasta los que desempeñan magistraturas, cargos o servicios inferiores a estos, pueden hacer gran daño si no se les tributan los debidos obsequios; ¿y los sátrapas y ministros del aire y de la tierra solo podrán hacérnoslo ligero si se los ultraja?". Es de ver cómo introduce Celso, a la manera humana, sátrapas del

12 Hipólito, Refutaciones VIII, 10, 3, en: J. Montserrat Torrents, Los gnósticos. Textos II (Madrid, Gredos, 2002), 229s.

13 Cfr. Ireneo, Adv. haer. I, 2, 6.

14 Cfr. Ireneo, Adv. haer. I, 4, 5.

15 Cfr. Clemente de Alejandría, ET 34, 1; 35, 1; 40-41; 44, 1.

16 Ireneo, Adv. haer. I, 2, 6 in fine.

17 Cfr. Clemente de Alejandría, ET $23,2$. 
Dios supremo, gobernadores, generales y procuradores y hasta los que desempeñan magistraturas, cargos y servicios inferiores, todos con ánimo de infligir graves daños a quienes los agravien...» ${ }^{18}$.

En un texto de la Epistola a Reginos o Tratado sobre la resurrección, se aplica tal doctrina a los hombres a partir de la Iluminación y se da por sobreentendido su destino común al de los ángeles, a pesar de que no se los mencione:

«Entonces, por lo tanto, como dijo el Apóstol: "Hemos sufrido con Él, hemos resucitado con Él y hemos subido al cielo con Él”"19. Pero si somos manifestados en este mundo, al revestirle somos sus rayos y somos abrazados por Él hasta nuestro ocaso, que es nuestra muerte en esta vida. Somos atraídos al cielo por Él como los rayos por el sol, no siendo refrenados por nada. Esta es la resurrección espiritual que absorbe a la psíquica del mismo modo que a la carnal» ${ }^{20}$.

Esta imagen de los rayos y el sol llegó a ser muy común tanto entre los gnósticos como entre los cristianos alejandrinos ${ }^{21}$, los de las Odas de Salomón ${ }^{22}$ y los judeocristianos ${ }^{23}$. Con estos ejemplos puede comprobarse cuán difundida estaba la teología solar entre los primeros cristianos ${ }^{24}$.

18 Orígenes, Contra Celso VIII, 35; versión española con introducción y notas por Daniel Ruiz Bueno (BAC, Madrid 1967), 548s.

19 Se combinan aquí varios textos paulinos: Ro. 6, 5-8; II Cor. 4, 10-14; Ef. 2, 5-6; Col. 2, 12-13; II Tim. 2, 11-12. Según la doctrina de San Pablo, la pasión, resurrección y ascensión de Jesús al cielo actúan como paradigma de las nuestras.

20 Tratado sobre la resurrección (Epistola a Reginos) (NHC I 4) I, 45, 28-46, 1; en: A. Piñero, J. Montserrat Torrents, F. García Bazán, Textos gnósticos. Biblioteca de Nag Hammadi III: Apocalipsis y otros escritos (Trotta, Madrid 2000), $206 \mathrm{s.}$ Cfr. Clemente de Alejandría, Protréptico IX, 84, 2: “Despierta”, dice, "tú que duermes, levántate de entre los muertos y Cristo el Señor te iluminará”(Ef. 5, 14). Es el sol de la resurrección, engendrado "antes del lucero de la mañana" (Sal. 109, 3), el que regaló la vida con sus propios rayos».; versión española con introducción y notas de Ma. Consolación Isart Hernández (Gredos, Madrid 1994), 153.

22 Cfr. Odas de Salomón 7, 14: «Puso sobre ella las huellas de su luz y caminó desde el principio hasta el final"; 11, 11: "El Señor me renovó con su vestidura y tomó posesión de mí con su luz»; 11, 13-14: «El Señor, como el sol sobre la faz de la tierra, ha iluminado mis ojos y mi rostro recibió el rocío»; en: A. Diez Macho, Apócrifos del Antiguo Testamento III (Cristiandad, Madrid 1982), 75, 79.

23 Cfr. Homilias pseudoclementinas XVIII, 10, 4.

24 Para mayor abundancia en este tema, véase A. Orbe, La teología del Espíritu Santo. Estudios Valentinianos IV (Analecta Gregoriana, Roma 1966), 659ss. 
La noticia de Hipólito presenta también reminiscencias de la teoría estoica del conocimiento visual, en cuya producción interviene la potencia anímica del Lógos o Hegemonikón y la del objeto visible. El alma lanza desde el cerebro un rayo que pasa por el orificio de la pupila y se extiende a la manera de un cono cuya base se encuentra en el campo visual al que se dirige la mirada y su vértice en la misma pupila. Séneca explica esta proyección a través de la teoría de la intentio, según la cual los ojos lanzan en un instante un rayo sobre mucha distancia y una misma voz repercute al mismo tiempo en todas las ciudades ${ }^{25}$.

Los gnósticos eran también eximios conocedores de la medicina de la época y, como tales, eran conscientes del uso del término sýstole en la obra de Galeno, especialmente en lo tocante a la contracción del útero en las enfermedades de las mujeres, cuya descripción por parte del médico de Pérgamo fue provechosamente utilizada en el mito que describe el páthos de Sophía ${ }^{26}$.

Para no anonadar con su gloria, el Logos contrajo sus rayos en señal de condescendencia a favor de la debilidad humana. Tal sýstole del Espíritu en el Logos, lejos de indicar un menoscabo de su divinidad, implica una concentración de la misma sobre sí.

En el texto de Ireneo, esta retracción de la potencia divina es interpretada como un silencio del Logos que el lugdunense advierte tanto en la escena de la triple tentación del desierto como en la de la pasión y crucifixión. Sus adversarios dicen muy poco acerca de la primera, más allá de su carácter ejemplar respecto de nuestras propias tentaciones ${ }^{27}$. Ireneo, en cambio, lo registra con claridad:

25 Cfr. SÉneCa, Cuestiones naturales II, 9, 1, en: Lucio Anneo Seneca. Obras completas, discurso previo, traducción y notas por Lorenzo Riber (Aguilar, Madrid 1957), 806. Para la teoría estoica del conocimiento sensible, véase E. Elorduy, El estoicismo I (Gredos, Madrid 1972), 170ss.

26 Cfr. Galeno, De locis affectis VI, 417-420; utilizamos la versión española Sobre la localización de las enfermedades con introducciones de Luis GARCía BALLESTER y traducción y notas de Salud Andrés Aparicio (Gredos, Madrid 1997), 414420. Para la teoría del «útero errante» y su aplicación en el mito gnóstico, véase $F$. García Bazán, Presencia y ausencia de lo sagrado en Oriente y Occidente (Biblioteca Nueva, Madrid 2001), cap. III: «Androginia y lenguaje de la sexualidad entre los gnósticos", 97-126.

27 Cfr. A. Orbe, Cristología gnóstica II, 13. 
«Pues cuando lo tentó (el diablo) diciéndole: "Si eres Hijo de Dios haz que estas piedras se conviertan en pan”, el Señor lo rechazó citando un precepto de la Ley: "Está escrito: no solo de pan vive el hombre" (Mt. 3, 3-4; Dt. 8, 3). En cuanto a la condición "si eres Hijo de Dios”, guardó silencio; en cambio, encegueció al tentador confesándose hombre, y mediante la palabra del Padre le vació su argumento» ${ }^{28}$.

Los gnósticos se explayaban más en la escena de la pasión, en la que introducían la compleja doctrina de la crucifixión del Cristo superior, en la que la Cruz celeste es paradigma de la terrestre. Ireneo, por su parte, ridiculiza a los valentinianos por el hecho de que no se vean obligados a dar razón en el paradigma celeste de los detalles que acompañan a la escena del Calvario:

«Además se contradicen cuando afirman que la pasión del Señor es figura de la expansión del Cristo superior, por la cual este se extien-

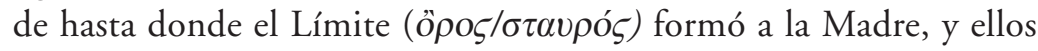
mismos se refutan al no poder continuar la semejanza de la figura. ¿Dónde al Cristo de arriba se le dio vinagre por bebida? ¿Dónde se le atravesó de modo que saliera sangre y agua? ¿O dónde sudó gotas de sangre? Y podríamos continuar con todo aquello que los profetas anunciaron sobre él» ${ }^{29}$.

Coincide no obstante con sus enemigos en que el silencio del Verbo o sýstole del Espíritu fue una estrategia para otorgar a sus verdugos una aparente victoria por la cual sería conducido mansamente a la muerte, necesaria para la salud de los hombres.

Teódoto lo expresa con claridad en el texto citado ${ }^{30}$ al decir que «La muerte, sin embargo, ha sido dominada con un engaño ( $\delta$ ó $\lambda \omega \delta_{\iota} \dot{\varepsilon}$ $\vartheta \alpha ́ v \alpha \tau o \zeta \kappa \alpha \tau \varepsilon \sigma \tau \rho \alpha \tau \eta \gamma \eta ́ \vartheta \eta) »$. El verbo $\kappa \alpha \tau \alpha \sigma \tau \rho \alpha \tau \eta \gamma \dot{\varepsilon} \omega$ significa «vencer por medio de una táctica». Esto es completamente coherente con la denominación con que Teódoto nombra al Salvador: «el gran luchador (ó $\mu \dot{\varepsilon} \gamma \alpha \varsigma \alpha \dot{\alpha} \omega v \imath \sigma \tau \eta ́ \varsigma){ }^{31}$. Como tal, recurre frente a la muerte a una estratagema tal que, entregándose a ella, consigue dominarla.

\footnotetext{
28 Ireneo, Adv. haer. V, 21, 2.

29 Ireneo, $A d v$. haer. IV, 35, 3.

30 ET 61, 6-7.

31 Cfr. ET 58, 1.
} 
La sýstole valentiniana comporta la suspensión de la realización de milagros, tal como ocurría antes del bautismo, en que Jesús recibió en el Jordán el "Espíritu de la intención del Padre» ${ }^{32}$ y que al momento de la pasión se replegó para dejarlo expuesto a la muerte. Al establecer la identidad entre el Espíritu Santo y la Vida, los valentinianos de Teódoto explican por qué la muerte no se hubiera atrevido a abordarlo de no ausentarse aquel.

«Por este motivo el compasivo, el fiel, Jesús, aceptó con paciencia los sufrimientos hasta que tomó este libro (el libro que vive del Viviente) puesto que sabe que su muerte es vida para muchos... ¡Oh, sublime enseñanza! Se humilló hasta la muerte, aunque la vida eterna reviste» ${ }^{33}$.

«Pero a los que [nacie] ron como un hombre invisible de modo invisible, los instruyó también invisiblemente sobre sí mismo, ya que no solo asumió por ellos la muerte de los que pensó salvar, sino tam[bién] su pequeñez, a la que han descendido cuando nacieron en cuerpo y alma; la asumió igualmente para esto, porque permitió ser concebido y engendrado como un infante en cuerpo y alma ${ }^{34}$.

La pérdida de los efectos de la gnosis sobre la carne, explica para los heterodoxos la sensación de abandono que lo hace clamar a Jesús desde el madero. "Dios mío, Dios mío, ¿por qué me has desamparado?» (Mt. 27, 46). Según el Evangelio de Felipe, el Jesús pasible de la economía se dirige con este grito no al Dios Desconocido, sino al Cristo superior que se extendió a la manera de una diástole sobre él en el Jordán, para asistirlo desde aquel momento hasta la noche de la última cena, en que se ausentó dinámicamente de él para que pudiera entrar en el reino de la muerte.

32 Cfr. Clemente de Alejandría, ET 16: «También la paloma (Mt. 3, 16) ha sido vista como cuerpo, a la que unos llaman el Espíritu Santo, pero los basilidianos "servidor" y los valentinianos el "Espíritu de la intención del Padre", (el que) ha cumplido su descenso sobre la carne de la palabra» En: F. GARCía BAZÁn, La gnosis eterna I, 231.

33 Evangelio de la Verdad (NHC I 3) 20, 10-28, en: A. Piñero, J. Montserrat Torrents, F. García BazÁn, op. cit. II: Evangelios, hechos cartas (Trotta, Madrid 1999), 149.

34 Tratado tripartito (NHC I 5) 115, 4, en: J. Montserrat Torrents, F. García BAZÁN, ibidem I: Tratados filosóficos y cosmológicos, 200g. 
“"Dios mío, Dios mío, ¿por qué, Señor, me has abandonado?” Esto lo dijo en la cruz, pues se había separado de allí [...] que fue engendrado por el que $[\ldots]$ mediante Dios $\aleph^{35}$.

La interpolación del término «Señor» en la expresión de Jesús, se explica por el contexto, pues, «lo engendrado mediante Dios» es Adán o el Cristo superior, quien quedó en el Pleroma. Por otra parte, lo que «se había separado» es Eva o Sophía, lo femenino e imperfecto. La cruz es el límite o hóros que separa la región de la plenitud de la cósmica, y desde allí es Eva quien clama por medio de Jesús crucificado, a aquel a quien reconoce como Señor y de quien se siente separada por la cruz.

Tal suspensión de la dýnamis divina sobre la carne de Jesús explica la manera en que el Evangelio de Pedro interpreta el grito desde la cruz:

«Y el Señor clamó diciendo: “¡Fuerza mía, oh fuerza, tú me has abandonado!". Y dicho esto fue asumido $(\dot{\alpha} v \varepsilon \lambda \dot{\eta} \varphi \vartheta \eta){ }^{36}$.

Un poco más atrás, el mismo evangelio hace referencia al silencio de Jesús durante la pasión:

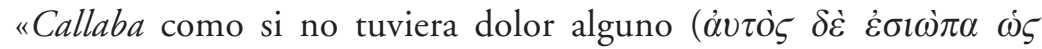
$\mu \varepsilon \delta \dot{\varepsilon} v \pi$ òvov $\tilde{\varepsilon} \chi(\omega v) »^{37}$.

\section{CONSIDERACIONES FINALES}

Lo que los valentinianos llaman sýstole, «contracción» o ausencia dinámica del Logos respecto del Jesús histórico, Justino e Ireneo lo entienden como un silencio del Verbo. El texto estudiado de San Ireneo presenta las tensiones e intercambios característicos de su estilo. El Logos, la Palabra, paradójicamente callaba, como si no fuese tal. Por otra parte, su humanidad, la carne, se dejaba absorber en la gloria de la resurrección, como si no fuese pasible y mortal. La unidad entre Hijo de Dios e Hijo del hombre queda acentuada por ese intercambio de roles que el Lugdunense denuncia en el texto, pues ni el Hijo de Dios desaparece cuando arrecian la tentación, la pasión y la muerte, que atañen a lo exclusivamente humano, ni la carne del Hijo del hombre deja de ser tal por

35 Evangelio de Felipe 68, 29, en: J. Montserrat Torrents, F. García Bazán, ibidem II, 40 .

36 Evangelio de Pedro (fragmento de Akhmín) V, 19, en: A. SÁnchez Otero, Los evangelios apócrifos, edición crítica y bilingüe (BAC, Madrid 2003), 370.

37 Ev. P. V, 10, ibidem. 
estar asumida, absorbida o devorada en la resurrección y ascensión, que conciernen a lo específicamente divino. De este modo Ireneo anticipa las intuiciones más elaboradas sobre la unión hipostática que habrían de llegar más tarde en la historia de la especulación cristiana y, a la vez, extrema su posición antidocetista.

Pero al coincidir en un punto con su predecesor Justino, armoniza también con sus contendientes gnósticos al considerar que tal silencio del Logos fue un ardid del Salvador para que, en cuanto hombre, resultara susceptible de los padecimientos físicos y la "forma de siervo" de la que habla Flp. 2, $7^{38}$ pudiera eclipsar la gloria de la divinidad y permitiera el triunfo ilusorio de la muerte, necesaria para la economía de la redención. Tanto el obispo de Lyon como los gnósticos, justifican así lo que siglos atrás anunció el profeta Sofonías cuando dijo:

«El Señor está en medio de ti,

¡un poderoso salvador!

Exulta de gozo por ti.

Callará de amor ${ }^{39}$.

38 «Se despojó a sí mismo tomando la forma de siervo».

39 Soph. 3, 17. En la última expresión el texto hebreo mantiene toda su fuerza (la raíz שרח), la que se pierde en el texto griego que la cambia por: "con su amor te dará nueva vida» Cfr. E. Jenni, C. Westermann Diccionario teológico manual del Antiguo Testamento I (Madrid, Cristiandad, 1978), 887. 
Resumen: La aparente suspensión de la actividad divina durante la pasión y muerte de Jesús llamó la atención de los primeros cristianos. Si bien Justino e Ireneo interpretan el supuesto abandono de la potencia divina en los momentos cruciales de la redención como un "silencio" del Logos, el obispo de Lyon extiende retrospectivamente tal actitud del Verbo encarnado hacia el episodio de las tentaciones en el desierto. Los gnósticos, coincidiendo con los eclesiásticos, hablan de una sýstole divina o ausencia dinámica del Logos respecto del Jesús histórico, a los efectos de que se hiciera posible el triunfo ilusorio de la muerte como paso necesario para la economía de la salvación.

Palabras clave: Justino, Ireneo, gnósticos, silencio, ausencia divina, teología solar

Abstract: The apparent suspension of the Divine activity during Jesus passion and death called the attention of the Early Christians. Although Justin Martyr and Irenaeus understand the supposed abandonment of the Divine power on crucial moments of the redemption as a "silence" of Logos, the Bishop of Lyon lengthens, in retrospective, that attitude of the Incarnate Word towards the episode of the temptations in the desert. The Gnostics, in agreement with the ecclesiastical Christians, speak of divine systole or dynamic absence of Logos with regard to the historical Jesus so as to make the illusory triumph of death necessary for the salvation economy.

Key words: Justin, Irenaeus, Gnostics, silence, divine absence, solar theology. 
